\title{
An application of multicriteria decision aid models in the prediction of open market share repurchases
}

\author{
Dimitrios Andriosopoulos ${ }^{1}$, Chrysovalantis Gaganis ${ }^{2}$, Fotios Pasiouras ${ }^{3 *}$, Constantin \\ Zopounidis $^{3}$ \\ ${ }^{1}$ Hull Business School, Hull University, United Kingdom \\ ${ }^{2}$ Department of Economics, University of Crete, Greece \\ ${ }^{3}$ Financial Engineering Laboratory, Department of Production Engineering and \\ Management, Technical University of Crete, Greece
}

\author{
Published in OMEGA \\ DOI:10.1016/j.omega.2012.01.009
}

\begin{abstract}
This study presents the first attempt to develop classification models for the prediction of share repurchase announcements using multicriteria decision aid (MCDA) techniques. We use three samples consisting of $434 \mathrm{UK}$ firms, 330 French firms, and 296 German firms, to develop country-specific models. The MCDA techniques that are applied for the development of the models are the UTilités Additives DIScriminantes (UTADIS) and the ELimination and Choice Expressing REality (ELECTRE) TRI. We adopt a 10-fold cross validation approach, a resampling technique that allows us to split the datasets in training and validation subsamples. Thus, at the first stage of the analysis the aim is the development of a model capable of reproducing the classification of the firms considered in the training samples. Once this stage is completed, the model can be used for the classification of new firms not included in the training samples (i.e. validation stage). The results show that both MCDA models achieve quite satisfactory classification accuracies in the validation sample and they outperform both logistic regression and chance predictions. The developed models could provide the basis for a decision tool for various stakeholders such as managers, shareholders, and investment analysts.
\end{abstract}

Keywords: Multicriteria, Share repurchases, announcements, prediction models

\footnotetext{
* Author for correspondence. E-mail: pasiouras@dpem.tuc.gr ; Tel: +30-28210-37239
} 


\section{Introduction}

The last two decades have witnessed a dramatic increase in the use of share repurchases. For example, as Grullon and Michaely (2002) highlight, expenditures on share repurchase programs (relative to total earnings) increased from $4.8 \%$ in 1980 to $41.8 \%$ in 2000, while more recent data from Standard and Poor's show that share repurchases among companies that comprise the S\&P 500 reached a record $\$ 172$ billion during the third quarter of 2007. In the EU-15, the value of share repurchases of industrial companies increased from 6.15 billion Euros in 1989 to 58.84 billion Euros in 2005, with their value over the entire period reaching 252.94 billion Euros (von Eije and Megginson, 2008). Given the growth in the importance and popularity of share repurchases, it is not surprising that this topic has attracted considerable attention in the literature, with numerous studies examining the short-and long-run valuation effects (e.g. Ikenberry, et al., 1995; McNally and Smith, 2007) as well as the determinants and motives of share repurchases (e.g. Grullon and Michaely, 2002; Baker et al., 2003).

In the present paper we deviate from existing studies by proposing the application of multicriteria decision aid (MCDA) techniques in the development of classification models for the prediction of firms' announcements of open market share repurchases. ${ }^{1}$ While past studies have employed MCDA techniques in other finance and accounting problems such as bankruptcy prediction, mergers and acquisitions, auditing, etc. with promising results (e.g. Doumpos and Zopounidis, 2001; Pasiouras et al., 2007a; Ioannidis et al., 2010), there is a lack of studies focusing on share repurchases announcements, and we aim to close this gap in the literature. The development of such a model is necessary because it is not possible to use models built for other important business events (e.g. bankruptcy) or to draw any conclusions from their application. There are two reasons for this. First, the decision makers (e.g. analysts, investors, etc) have different objectives, and the models are built with different goals in mind. Second, different business events are being driven

\footnotetext{
${ }^{1}$ Obviously, the purpose of this study is not the development of a new MCDA technique (see e.g. Zopounidis and Doumpos, 2000; Doumpos and Zopounidis, 2004a), the exhausted comparison of alternative techniques based on simulations (e.g. Doumpos et al., 2009) or comparisons of a more theoretical nature (Doumpos and Zopounidis, 2011). However, since our sample involves a set of real alternatives (i.e. firms), our study offers some indications as for the ability of the MCDA methodologies to infer accurate models from real data in a decision making problem that has not been examined before within this context, and the characteristics of which are difficult, if not impossible, to be reproduced in a simulated environment.
} 
by different factors and theoretical reasoning, and as such the underlying variables (criteria) also differ. As we discuss in more detail in Section 4, a model with the ability to predict share repurchases could have practical implications for various decision makers (e.g. existing shareholders, prospective investors and peer firm managers), and especially for investment managers who could use it as the basis for an investment strategy.

While some studies have tried to explain the determinants of share repurchases (e.g. Baker et al., 2003), to the best of our knowledge, up to date only Andriosopoulos (2011) tests the out-of-sample prediction accuracy of his model using logistic regression. ${ }^{2}$ However, the MCDA methods proposed in the present study pose various advantages over traditional statistical and econometric methods such as discriminant analysis and logistic regression. For example: (i) they do not make any assumptions about the normality of the variables or the group dispersion matrices, (ii) they are not sensitive to multicollinearity or outliers, (iii) they can easily incorporate qualitative data, and (iv) they are also very flexible in terms of incorporating any preferences of the decision maker.

We use a sample of 530 open market share repurchases that were announced in France, Germany and the UK between 1997 and 2006 and an equally matched control group. There are a number of reasons for which we focus on these three counties. First, they are the three largest economies in the EU, in terms of GDP, number of listed companies, etc. Therefore, some of the largest and most important European firms operate in these three countries. Second, data from von Eije and Megginson (2008) indicate that over the period 1989-2005, these three countries accounted for a combined $76.16 \%$ of the total value of share repurchases by industrial firms in the EU-15 (UK: 49.38\%, France: 19.95\%, Germany: 6.82\%). Thus, our study provides an extensive coverage in terms of open market share repurchases in the EU. Third, there are important differences between these countries. For instance, the majority of U.K. firms are widely held companies whereas France and Germany have a more

\footnotetext{
${ }^{2}$ The focus of studies on the determinants of share repurchases, which traditionally use econometric techniques, lies on the significance of the overall explanatory power of the model and the significance of the coefficients of the variables, while no attention is given to the classification ability of the model. However, when the objective is the development of a classification model for distinguishing between repurchasing and non-repurchasing firms, as in the present study, the focus of interest is on whether the firms can be correctly classified, especially in a holdout sample. Thus, these two strands of the literature, approach the problem from a quite different perspective.
} 
concentrated ownership structure, of which France has a higher level of ownership concentration compared to Germany (La Porta et al., 1999). Hence, differences in the level of shareholder protection can potentially lead to different managerial attitudes towards shareholder value maximisation. Consequently, this could result in different attitudes on firms' cash utilisation and the choice of firm payout decisions. For example, in France firms tend to be family owned and in Germany firms are less widely held than U.K. firms. Thus, it is likely that share repurchases in Germany, and especially in France, would not be such a popular payout mechanism as it is in the U.K. Moreover, managers have different attitudes and priorities in different countries regarding the management of their firms. For instance, Brounen et al. (2004) find that shareholder wealth maximisation is one of the most significant priorities for managers in the U.K. In contrast, managers in Germany and France place more emphasis on other factors such as leverage optimisation. Finally, the magnitude of the market reaction to the announcement of the intention to repurchase shares in the open market differs significantly among these countries (see e.g. Lasfer, 2005; Ginglinger and L'Her, 2005) suggesting that differences in the operating environment can have a significant impact on the markets' perception and reaction to such announcements, as well as the managerial incentives and implications for making such announcements. Thus, the simultaneous application of the MCDA techniques in these three countries, allows us to test their usefulness in different institutional and regulatory settings, and in countries with potentially different managerial attitudes. ${ }^{3}$

We develop two MCDA models for each country, using the UTilités Additives DIScriminantes (UTADIS) and ELimination and Choice Expressing REality (ELECTRE) TRI methods. These two methods use different modeling forms (i.e. value functions and outranking relations), thus enabling the investigation of the generalizing ability of different MCDA models in the prediction of share repurchases. For benchmarking purposes we compare the classification accuracies of the MCDA models with the ones obtained by logistic regression. Thus, we develop a total of nine models. All the models are estimated and tested using a ten-fold cross-validation approach. Our results show that the MCDA models classify correctly around $70 \%$ of

\footnotetext{
3 The comparison of the results obtained across different studies would not be possible due to differences in the datasets, the time period, the methods used to validate the models, the employed variables, and so on. In other words, there would be no common basis for such a comparison.
} 
the firms in the validation sample, and they outperform logistic regression in all the cases.

The remaining of this research study is organised as follows. Section 2 presents the data, variables and methodology. Section 3 provides a discussion of the empirical results. Section 4 discusses the practical usefulness of the developed models. The conclusions are in Section 5.

\section{Data, Variables and Methodology}

\subsection{Data}

This study considers a total of 530 repurchasing firms and 530 non-repurchasing control firms, operating in France, Germany and the UK. The sample was constructed as follows. First, we identified all the announcements of intention to repurchase ordinary shares in the open market, using news articles posted in Perfect Analysis and Factiva databases from $1^{\text {st }}$ January 1997 until $31^{\text {st }}$ December $2006 .{ }^{4}$ Then, information on the share prices and accounting data was obtained from DataStream and Worldscope. Finally, repurchasing firms with available accounting and stock market data were randomly matched by country and year with a control sample of domestic firms that have not made an open market share repurchase announcement between 1997 and 2006. This procedure resulted in three country-specific samples consisting of 434 UK firms, 330 French firms, and 296 German firms.

Table 1 presents information on the number of firms in the samples by year and country. One can see that in France and Germany the number of share repurchase announcements shows a large increase in 1998 (in France) and 1999 (in Germany). This is due to the fact that share repurchases as a payout mechanism was prohibited in these two countries prior to 1997.

\section{[Insert Table 1 Around Here]}

\footnotetext{
${ }^{4}$ The study focuses on this period because it was not until 1998 that share repurchasing was allowed to take place more freely in both Germany and France. The Perfect Analysis and Factiva databases report any news announcements that were available in the press made by UK and European firms. Only firms that announced their intention to repurchase ordinary shares in the open market were included in the sample. The list of repurchasing firms that formed our starting basis was initially used in the study of Andriosopoulos (2011).
} 


\subsection{Variables}

As it is always the case, there is a large list of financial variables that could be used in the development of an empirical model. However, from a practical point of view, when designing a classification model, one has to consider the trade-off between the level of information that will be captured, input requirements, and over-fitting (Kocagil et al., 2002). More detailed, developing a model that includes a large number of variables poses problems related to an increase in time and cost of data collection and management. At the same time, adding more variables in the model will not necessary increase its prediction ability as the new variables may be correlated with the ones already in the model, offering very little information. An alternative used by some studies is to start from a large list of variables and reduce them on the basis of stepwise procedures. However, Palepu (1986) criticizes this approach as being arbitrary and leading to the statistical over-fitting of the model to the sample at hand, and he suggests the selection of a limited set of variables on the basis of the most frequently mentioned hypotheses. ${ }^{5}$

In the light of these arguments, in the present study we select a limited and carefully selected number of variables while relying on theories that have been proposed to explain the potential motives for a share repurchase, such as undervaluation signaling, the agency problems of free cash flows, the capital market allocation hypothesis, and the tax motivated substitution for dividends. In the discussion that follows we briefly outline the contending hypotheses that underlie share repurchases and we discuss the rationale for their inclusion in the present study. ${ }^{6}$

Firms may decide to distribute their excess cash back to their shareholders via cash dividends or share repurchases in the open market. However, open market share repurchases can be considerably more flexible as a payout method compared to

\footnotetext{
${ }^{5}$ The study of Palepu (1986) deals with the prediction of acquisition targets, but his comment is of a more general nature, and it is clearly applicable in our case as well. Furthermore, the same criticism is applicable to the use of univariate tests (e.g. Kruskal-Walis, t-test) to screen the variables that will be used in the model, as the selection depends on the specific sample, decreasing the generalization ability of the model.

${ }^{6}$ The selected variables are commonly used in empirical studies focusing on payout policies and share repurchases in the U.S., Canada and Europe alike. Obviously, one could also include non-financial variables, used in recent studies such as corporate governance mechanisms (e.g. Huang-Hsi et al., 2010). However, such data were not available in our case. We hope that future research will improve upon this.
} 
dividends, and existing evidence suggests that firms are more likely to repurchase their stock when they have high cash flows and low investment opportunities (Dittmar, 2000; Mitchell and Dharmawan, 2007). As in Dittmar (2000) and Andriosopoulos (2011) to proxy for firms' excess cash, we use the variable "cash" defined as the ratio of net operating income before taxes and depreciation to total assets at the year-end prior to the repurchase announcement.

Furthermore, for capturing both a firm's growth opportunities and excess cash flow, we follow Opler and Titman (1993) and Mitchell and Dharmawan (2007) and construct a dummy variable that takes the value of one for firms that have simultaneously low Tobin's $q$ (lower than the median $q$ of a firm's respective industry for each respective year) and high cash flow (higher than the median cash flow of the respective industry for each year) and the value of zero otherwise (free cash flow dummy).

To investigate the impact of undervaluation on the likelihood to announce an open market share repurchase, we follow Ikenberry et al. (1995), Ikenberry et al. (2000), Barth and Kasznik (1999), and Dittmar (2000), and we include as a proxy for potential undervaluation, that is the market-to-book ratio at the year-end prior to the share repurchase announcement $(M K B K)$.

The decision to distribute excess capital as a payout to shareholders through a share repurchase reduces a firm's equity capital, which in turn increases its leverage ratio. Consequently, Bagwell and Shoven (1988) and Hovakimian et al. (2001) argue that a share repurchase programme displays the managers' preference to employ debt instead of equity, so that they can approach their target leverage ratio. Indeed, a number of empirical studies report evidence that firms with low leverage are more likely to repurchase their shares (Hovakimian et al., 2001; Mitchell and Dharmawan, 2007; Dittmar, 2000). Therefore, we employ the variable "leverage" defined as the ratio of total debt to total assets at the year-end prior to the repurchase announcement.

Vermaelen (1981) argues that smaller firms are more likely to have higher information asymmetries, since they are less scrutinised by analysts and the media. Consequently, smaller firms are more likely to be misvalued, which leads to a greater likelihood of repurchasing their shares. In line with this argument are the findings of Mitchell and Dharmawan (2007) who report that firms which are small and announce their intention to repurchase a large fraction of their outstanding capital, have a 
significant signalling impact. In addition, Dittmar (2000), Grullon and Michaely (2002), and Ikenberry et al. (1995) report evidence that size has a positive relationship with the volume of share repurchases. Hence, size is a firm specific characteristic, which can have a significant impact on the likelihood to announce an open market share repurchase. To capture the impact of size on the repurchasing decision we use the variable "size" defined as the natural logarithm of a firm's total assets at the year-end prior to the share repurchase announcement.

Typically, capital gains tax rate is lower than the respective personal income tax rate. Therefore, share repurchases can have a significant advantage over cash dividends, from a tax perspective. More detailed, the personal tax savings hypothesis, states that share repurchases can be more tax efficient and more beneficial to shareholders, compared to cash dividends (Grullon and Michaely, 2002). While Bagwell and Shoven (1989) and Dittmar (2000) find no evidence of taxation having a significant impact on corporate payouts, a number of research studies do find evidence of tax having a significant influence on firms' decision making on payouts, and of the market having a favourable reaction due to the tax impact (Grullon and Michaely, 2002). Furthermore, open market share repurchases can have advantages relative to cash dividends such as a tax differential and that they do not pose a commitment to the firm. Consequently, open market share repurchases can be considered to be substitutes to cash dividends (Grullon and Michaely, 2002). Therefore, we assume that a firm's payment of dividends can have a significant discriminatory ability that will help in determining a firm's propensity to announce an open market share repurchase. We follow Dittmar (2000) and Jagannathan and Stephens (2003), and we employ the proxy variable "cash dividends", which is defined as the ratio of total regular cash dividends relative to net income. Finally, for incorporating the tax impact in our models, we follow McNally (1999) and we proxy for the average tax rate with the proxy variable "dividend yield", which is the ratio of total cash dividends divided by the market value at the year-end prior to the repurchase announcement.

Finally, for capturing the potential impact that a firm's profitability and operating performance may have on the likelihood to announce an open market share repurchase (Grullon and Michaely, 2004), we employ the variable return on assets " $R O A$ ", which is calculated as the ratio of net income to total assets. 


\subsection{Multicriteria classification methods}

The problem considered in this study falls within the multicriteria classification problematic, which, in general involves, the assignment of a finite set of alternatives $\mathbf{x}_{1}, \mathbf{x}_{2}, \ldots, \mathbf{x}_{n}$ to a set of $q$ classes $C_{1} \succ C_{2} \succ \cdots \succ C_{q}$. Each alternative is described by $m$ criteria (i.e. independent variables) and consequently it can be considered as a multivariate vector $\mathbf{x}_{i}=\left(x_{i 1}, x_{i 2}, \ldots, x_{i m}\right)$, where $x_{i j}$ is the description of alternative $i$ on criterion $j$.

In the present study, the alternatives involve the 1,060 firms, the criteria correspond to the eight variables discussed in Section 2.2., and there are two classes. The two MCDA methods used in the present study, originate from different disciplines. The UTADIS method employs the framework of preference disaggregation analysis while the ELECTRE TRI method implements the outranking relations approach of multicriteria decision aiding (Roy and Bouyssou, 1993). ${ }^{7}$

At this point, it should be mentioned that an important issue of concern in evaluating the classification ability of a model is to ensure that it does not over-fit to the training (estimation) data set, and that its out-of-sample generalization ability is adequately assessed. In the present study, we adopt a 10 -fold cross validation approach to develop and evaluate the models. Under this approach, each one of the three samples of the 434 UK firms, the 330 French firms and the 296 German firms is initially randomly split into 10 mutually exclusive sub-samples (i.e. non-overlapping folds of approximately equal size). Then, for each case 10 models are developed in turn, using nine folds for training and leaving one fold out each time for validation. More detailed, in each of the 10 replications, the training samples consist of 391 firms in the case of the UK, 296 firms in the case of France, and 266 in the case of Germany. The validation (holdout) samples consist of not-the-same 43 firms (UK),

\footnotetext{
${ }^{7}$ Preference disaggregation analysis (Jacquet-Lagrèze and Siskos, 1982, 1983, 2001) refers to the analysis (disaggregation) of the global preferences (judgement policy) of the decision maker in order to identify the criteria aggregation model that underlies the preference result. Preference disaggregation analysis uses common utility decomposition forms to model the decision maker's preferences through regression-based techniques. More detailed, in preference disaggregation analysis the parameters of the utility decomposition model are estimated through the analysis of the decision maker's overall preference on some reference alternatives. The problem is then to estimate the utility function that is as consistent as possible with the known subjective preferences of the decision maker.
} 
33 firms (France), and 30 firms (Germany), respectively. The average error rate over all the 10 replications is the cross-validated error rate.

\subsubsection{UTADIS}

The UTADIS method develops an additive value function, which is used to score the firms and decide upon their classification. The value function has the following general form:

$$
U(\mathbf{x})=\sum_{j=1}^{m} w_{j} u_{j}^{\prime}\left(x_{j}\right) \in[0,1]
$$

where $w_{j}$ is the weight of criterion $j$ (the criteria weights sum up to 1) and $u_{j}^{\prime}\left(x_{j}\right)$ is the corresponding marginal value function normalized between 0 and 1 . The marginal value functions provide a mechanism for decomposing the aggregate result (global value) in terms of individual assessments on the criteria level. To avoid the estimation of both the criteria weights and the marginal value functions, it is possible to use the transformation $u_{j}\left(x_{j}\right)=w_{i} u_{j}^{\prime}\left(x_{j}\right)$. Since $u_{j}^{\prime}\left(x_{j}\right)$ is normalized between 0 and 1 , it is obvious that $u_{j}\left(x_{j}\right)$ ranges in $\left[0, w_{i}\right]$. In this way, the additive value function is simplified to the following form, which provides an aggregate score $U(\mathbf{x})$ for each firm along all criteria:

$$
U(\mathbf{x})=\sum_{j=1}^{m} u_{j}\left(x_{j}\right) \in[0,1]
$$

Comparing the value utilities with the cut-off thresholds, the classification of the firms is achieved as follows:

$$
\left.\begin{array}{cc}
U(\mathbf{x}) \geq t_{1} & \Rightarrow \mathbf{x} \in C_{1} \\
\ldots & \ldots \\
t_{k} \leq U(\mathbf{x})<t_{k-1} & \Rightarrow \mathbf{x} \in C_{k} \\
\ldots & \ldots \\
U(\mathbf{x})<t_{q-1} & \Rightarrow \mathbf{x} \in C_{q}
\end{array}\right\}
$$

The estimation of the additive value function and the cut-off thresholds is performed through linear programming techniques. The objective of the method is to 
develop the additive value model so that the above classification rules can reproduce the predetermined grouping of the firms as accurately as possible. Therefore, a linear programming formulation is employed to minimize the sum of all violations of the above classification rules for all the observations in the training sample. Doumpos and Zopounidis (2004b) provide a detailed description of the mathematical programming formulation. ${ }^{8}$

\subsubsection{ELECTRE TRI}

Within the context of classification problems, the outranking relation is used to estimate the outranking degree of an alternative $\mathbf{x}_{i}$ over a reference profile $\mathbf{r}_{k}$, which distinguishes the classes $C_{k}$ and $C_{k+1}$. Each reference profile $\mathbf{r}_{k}$ is defined as a vector of individual profiles for each criterion, i.e., $\mathbf{r}_{k}=\left(r_{k 1}, r_{k 2}, \ldots r_{k m}\right)$.

In order to determine whether an alternative $\mathbf{x}_{i}$ outranks a reference profile $\mathbf{r}_{k}$, all paired comparisons $\left(x_{i j}, r_{k j}\right)$ and $\left(r_{k j}, x_{i j}\right)$ should be performed for each criterion $j$. The former comparison enables the assessment of the strength $\sigma\left(\mathbf{x}_{i}, \mathbf{r}_{k}\right)$ of the affirmation "alternative $\mathbf{x}_{i}$ is at least as good as profile $\mathbf{r}_{k}$ ", while the latter comparison leads to the assessment of the strength $\sigma\left(\mathbf{r}_{k}, \mathbf{x}_{i}\right)$ of the affirmation "profile $\mathbf{r}_{k}$ is at least as good as alternative $\mathbf{x}_{i}{ }^{\prime \prime}$. An alternative $\mathbf{x}_{i}$ is preferred to a profile $\mathbf{r}_{k}\left(\mathbf{x}_{i} \mathrm{P} \mathbf{r}_{k}\right)$ if $\sigma\left(\mathbf{x}_{i}\right.$, $\left.\mathbf{r}_{k}\right) \geq \lambda$ and $\sigma\left(\mathbf{r}_{k}, \mathbf{x}_{i}\right)<\lambda$ ( $\lambda$ is a pre-specified cut-off point). If $\sigma\left(\mathbf{x}_{i}, \mathbf{r}_{k}\right) \geq \lambda$ and $\sigma\left(\mathbf{r}_{k}, \mathbf{x}_{i}\right) \geq \lambda$, then $\mathbf{x}_{i}$ and $\mathbf{r}_{k}$ are considered as indifferent $\left(\mathbf{x}_{i}\right.$ I $\left.\mathbf{r}_{k}\right)$. Finally, if $\sigma\left(\mathbf{x}_{i}, \mathbf{r}_{k}\right)<\lambda$ and $\sigma\left(\mathbf{r}_{k}\right.$, $\left.\mathbf{x}_{i}\right)<\lambda$, then $\mathbf{x}_{i}$ and $\mathbf{r}_{k}$ are considered incomparable $\left(\mathbf{x}_{i} \mathrm{R} \mathbf{r}_{k}\right)$. The estimation of the credibility index $\sigma\left(\mathbf{x}_{i}, \mathbf{r}_{k}\right)$ is performed in two stages (Roy and Bouyssou, 1993). The first stage involves the concordance test, which considers the criteria for which $\mathbf{x}_{i}$ is at least as good as $\mathbf{r}_{k}$. The second stage considers the veto conditions, which may arise if $\mathbf{x}_{i}$ is significantly worse than $\mathbf{r}_{k}$ in some criteria.

\footnotetext{
${ }^{8}$ As discussed in more detail in Doumpos and Zopounidis (2004b), the additive utility model developed through UTADIS is affected by some technical parameters involved in the solution process as well as the way that the piece-wise linear form of the marginal utility functions is considered (i.e. the way that each criterion's range is divided into subintervals). Since there is not a general guidance for determining the parameters this study compares the classification performance with respect to various values. As it common practice, the final values were selected on the basis of the classification accuracies achieved in the training sample over the 10-fold cross validation approach described in the text. This approach resulted in the number of subintervals being set equal to two in all three cases.
} 
Once the outranking relation is developed, the classification of the alternatives is performed through heuristic assignment procedures. For example, ELECTRE TRI employs two assignment procedures, the pessimistic and the optimistic one. Under the pessimistic assignment, in a classification problem with $q$ classes, each alternative $\mathbf{x}_{i}$ is compared successively to the profiles $\mathbf{r}_{1}, \mathbf{r}_{2}, \ldots, \mathbf{r}_{q-1}$. Let $\mathbf{r}_{k}$ be the first profile such that $\sigma\left(\mathbf{x}_{i}, \mathbf{r}_{k}\right) \geq \lambda$. Then, $\mathbf{x}_{i}$ is assigned to group $C_{k}$ (if there is no profile such that $\sigma\left(\mathbf{x}_{i}, \mathbf{r}_{k}\right) \geq \lambda$, then $\mathbf{x}_{i}$ is assigned to group $\left.C_{q}\right)$. In the case of the optimistic assignment each alternative $\mathbf{x}_{i}$ is compared successively to the profiles $\mathbf{r}_{q-1}, \mathbf{r}_{q-2}, \ldots, \mathbf{r}_{1}$. Let $\mathbf{r}_{k}$ be the first profile such that $\mathbf{r}_{k} \mathrm{P} \mathbf{x}_{i}$. Then, $\mathbf{x}_{i}$ is assigned to group $C_{k+1}$ (if the there is no profile satisfying the above condition, then $\mathbf{x}_{i}$ is assigned to group $C_{1}$ ). The differences between the two procedures appear in the presence of the incomparability relation. For instance, in a two-group case an alternative that is incomparable to the profile $\mathbf{r}_{1}$ will be assigned to group $C_{1}$ with the optimistic procedure and to group $C_{2}$ with the pessimistic procedure. Consequently, the differences between the two rules facilitate the identification of alternatives with special attributes, which make the comparison of the alternatives to the profiles difficult.

In the present study we experiment with both the optimistic and the pessimistic procedures while all the parameters of the ELECTRE TRI model (e.g. weights of the criteria, thresholds, etc.) are estimated by inferring outranking classification models from reference examples. In particular, we use the approach developed by Doumpos et al. (2009), which is based on the differential evolution optimization algorithm. The evolutionary process implements genetic operators (i.e. mutation, crossover, selection) to evolve an initial population of solutions, until a termination criterion is met. The differential evolution algorithm assumes that there is a generation of solutions and generates a mutant solution for each solution of the current generation. A crossover solution is also constructed combining the parent solution from the current generation with its associated mutant solution. At the selection stage the crossover solution is compared (in terms of fitness) to its parent and the best of the two is selected to be a member of the next generation. For the purposes of the present study, we adopt the settings proposed by Doumpos et al. (2009) on the basis of their large scale experimental analysis. In particular, we set the number of generations 
equal to 200 while the population size is set as twice the number of the estimated parameters (i.e. weight vector, thresholds, class limits, etc). The mutation constant and the crossover probability are selected after experimenting with values between 0 and 1 . These values were finally set at 0.6 on the basis of the classification accuracies achieved in the training sample of the 10-fold cross validation approach described earlier. ${ }^{9}$

\section{Empirical Results}

Table 2 presents descriptive statistics (median and standard deviation) along with the results of Kruskal-Wallis test of medians' differences between the two groups. The latter shows that in several cases the differences in characteristics between repurchasing and non-repurchasing firms vary significantly between countries. For example, consistent with our expectations cash and $R O A$ are higher for repurchasing firms in Germany and the UK, suggesting that repurchasing firms have higher levels of excess cash and are more profitable compared to non-repurchasing firms. Moreover, in France and Germany repurchasing firms have higher levels of excess cash and experience lower growth compared to non-repurchasing firms. We observe similar differences in the case of cash dividends and $M K B K$ across countries.

However, we also observe similarities across countries with the differences between the medians being statistically significant in the case of dividend yield, leverage, and size in all three countries. The results from Germany show that the repurchasing firms have lower leverage compared to non-repurchasing firms, implying that managers announce their intention to make an open market share repurchase in their attempt to exploit their firms' excess debt capacity. Hence, they can fine tune their firms' leverage ratio which is consistent with Grullon and Ikenberry (2000). In addition, this is consistent with the evidence reported in Brounen et al. (2004) who find that managers in Germany consider leverage optimisation to be highly important. This shows that the differences in institutional and regulatory

\footnotetext{
9 Doumpos et al. (2009) also end up with 0.6 as the most appropriate values, after some experimentation. With regards to the number of generations and the population size, Doumpos et al. (2009) mention that as the problem becomes more complex higher figures for these parameters would be more appropriate. However, they suggest limiting them to 200, to maintain the computational burden to acceptable levels. As they mention, this selection is confirmed by the high accuracy rates that were obtained even in the cases where the algorithm did not find the optimal solution.
} 
frameworks between countries can potentially have a significant impact on managers' decision to announce an open market share repurchase. Even though certain variables are not significant at a univariate level in all three countries, we retain them in the analysis during the development of the model, for two reasons: (i) to capture any potential effect they may have on managerial decisions when considered simultaneously with other variables, and (ii) to avoid developing a data-driven model that could over-fit to the data in hand (see section 2.2).

\section{[Insert Table 2 Around Here]}

The results obtained from the two MCDA methods are analyzed both in terms of the criteria (i.e. independent variables) weights and the classification accuracy of the models. Table 3 illustrates the contribution of the 8 criteria in each one of the country-specific models. The presented results correspond to the average weights (in percentage) over the 10 replications of the model development process described in section 2.3. We observe both similarities and differences between the two MCDA methods and across the three countries. For example, consistent with the univariate results, size appears to be the most important variable in the three models developed through the ELECTRE TRI method as well as in the UTADIS-UK model, while at the same time it is one of the most important variables in the UTADIS models developed for Germany and France. Similarly, cash dividends is the most important variable in the case of the UTADIS-Germany and UTADIS-France models, and one of the most important variables in the remaining cases. MKBK appears to have a moderate impact in most models, whereas other variables such as cash, leverage and free cash flow dummy are in general the least important ones. Turning to some differences, it appears that ROA is quite important in the UTADIS-UK model (weight of $35.86 \%$ ), while it is considerably less important in the remaining models. One of the most important variables in the case of Germany is the dividend yield which carries weights equal to $24.73 \%$ (UTADIS) and $21.17 \%$ (ELECTRE TRI).

The differences across the country-specific models developed with a given technique (e.g. UTADIS) could be attributed to country-specific characteristics (e.g. shareholder protection, ownership concentration) which shape managerial attitudes towards shareholder value and the choice of firm payout decisions. For example, as 
mentioned earlier, French firms tend to be more family owned, and German firms have higher levels of ownership concentration compared to the UK. Furthermore, as discussed in Brounen et al. (2004), UK firms consider shareholder wealth maximization as one of the most prominent priorities, which is not the case in France and Germany.

While there is no particular reason for the differences between the two MCDA models developed for a given country (e.g. UK), such differences among alternative classification methods have been observed in past classification studies in finance (e.g. Pasiouras et al., 2007b). One possible explanation is that although all methods attempt to classify correctly as many firms as possible, they consider different ways of processing the same information in the dataset. For instance, while the weights in the value functions developed with UTADIS represent tradeoffs, the weights in ELECTRE TRI represented the strength of the criteria in a weighted voting process. As discussed in Pasiouras et al. (2007b), whether the weights attributed by one method are intuitively more appealing than those selected by another method is a matter of subjective judgment. ${ }^{10}$

[Insert Table 3 Around Here]

Table 4 presents the classification results. Panel A corresponds to the training sample, while Panel B corresponds to the validation sample. At this stage we also perform a comparative analysis with the corresponding results obtained through logistic regression. Since the classification accuracies in the training sample are usually upwards biased we focus on the ones obtained in the validation sample.

\section{[Insert Table 4 Around Here]}

Our results can be summarized as follows. First, the models are quite stable, with the classification accuracies in the validation sample being only slightly lower than the ones obtained in the training sample. Second, while there is no clear winner

\footnotetext{
${ }^{10}$ In other words, the decision maker can first select the MCDA model that is closer to his beliefs (e.g. value functions vs outranking relations), and then to use the corresponding criteria weights in order to obtain the classification accuracies presented in Table 4.
} 
between UTADIS and ELECTRE TRI they both outperform logistic regression in all the cases in the validation sample. The best model is developed with UTADIS, achieving a quite satisfactory overall accuracy that is equal to $76.96 \%$. Third, it appears that the models developed for France are capable of classifying correctly a higher percentage of firms that then corresponding models developed for Germany and the UK. Actually, the results do indicate a fair amount of misclassification in the case of Germany which is around $33 \%$ to $37 \%$. Fourth, with the exception of the LRUK model, we observe that the models are capable in classifying better firms belonging in Group 1 (non-share repurchasing firms) rather than in Group 2 (share repurchasing firms). However, all the models are capable of achieving quite balanced accuracies, with the differences between the two groups being in general quite small.

As Barnes (1999) notes perfect prediction models are difficult to develop even in the bankruptcy prediction literature, where failing firms have definitely inferior or abnormal performance compared to healthy firms. The problem with the identification of firms that announce share repurchases is that are potentially many reasons for their decision, while at the same time managers do not always act in a manner which maximizes shareholder returns. Therefore, it is more reasonable to compare the performance of the models with chance assignments. Since we have equally matched samples, a naïve model based on random assignments would assign correctly $50 \%$ of the firms on average. Thus, we can conclude that all the developed models perform considerably better than chance.

\section{A note on the usefulness of the proposed models}

As mentioned earlier, during the development stage the aim of the models was to reproduce the classification of the firms considered in the training samples. The results in the validation sets, illustrated that the models can also be used for the classification of any new firm not included in the training sample, with a satisfactory accuracy. Therefore, as we discuss in more detail below, the developed models could be of use to various stakeholders that would be interested in the prediction of share repurchase announcements in the three largest EU economies, and in extension utilise the already well documented signalling effects that such announcements have. 
While there are no empirical studies demonstrating the extent of the benefits from using such models, one can point out various advantages. For example, existing empirical studies document large abnormal returns around the announcement day of share repurchases (e.g. Vermaelen, 1981) as well as in subsequent years (Ikenberry et al. 1995). Thus, from the perspective of a potential investor, the ability to predict share repurchases in advance, could form the basis for an investment strategy. More detailed, at the first stage of the analysis the developed models could allow the investment manager to identify potential repurchasing firms among the population of listed firms in UK, France and/or Germany. While, a more in-depth examination of some firms may be necessary, the employment of the models will definitely assist the investment manager to avoid difficulties in analyzing large quantities of data on a case-by-case basis, resulting in huge savings in terms of both money, and time. Then, the decision maker (e.g. individual investor or investment analyst/manager), could form a portfolio to include the stocks of the firms predicted by the models as belonging in the group of repurchasing firms, earning abnormal returns. ${ }^{11}$ Within this context, it is also likely that investment analysts/managers could use such a procedure as a defense in law suits since they could justify their recommendation on the basis of objective information and a properly developed quantitative model. ${ }^{12}$

However, the use of the models is not limited to investment managers. For example, from the perspective of an existing shareholder, the ability to predict share repurchases could be useful in his decision on whether to hold or sell his stocks in anticipation of such an announcement. Finally, from the perspective of a manager in any given firm, it may be useful to be in a position to predict in advance the repurchasing decision of peer firms. Furthermore, it may be of interest to the manager to know whether his firm is developing a profile similar to the average repurchasing firm, as this could be anticipated by the market, leading to changes in the share price.

The purpose of the above discussion is not to imply that the developed models can replace the decision makers. There are two reasons for this. First, despite achieving a satisfactory performance that clearly outperforms chance assignments, by

\footnotetext{
${ }^{11}$ This reason is also frequently mentioned as one of the main motives for the development of models for the prediction of acquisition targets (e.g. Powell, 1997; Ouzounis et al., 2009)

${ }^{12}$ See Laitinen and Laitinen (1998), Ramamoorti et al. (1999), Pasiouras et al. (2007a) among others for similar arguments in the case of the development of classification models to assist external auditors in issuing their opinion.
} 
classifying correctly about 7 (to 8 ) out of the 10 firms (i.e. accuracies around 70\%$80 \%$ ), the models do not classify correct all the firms. Of course, as mentioned earlier perfect models (i.e. with $100 \%$ out-of-sample accuracy) do not exist even in the case of bankruptcy prediction and credit risk modeling. Therefore, the models cannot and should not replace professional judgment, rather they can assist the decision maker by providing objective information that can be prove useful in an initial screening of the firms. Second, there are some issues that are not considered in the present models due to data unavailability such as the strategic goals, and the corporate governance of the firms. A potential investor or manager could examine these firm-specific characteristics after the initial screening to make up his final decision. In any case, it should be mentioned that the use of MCDA methods to make real - time decisions could be realized through the collaboration of researchers with decision makers. This would result in the development of even more powerful models that would fully capture the preferences of decision makers as regards the selection of the variables, their background knowledge, and their objectives. The development of multicriteira decision support systems could increase further the employment of such models on a daily basis.

\section{Conclusions}

This research study contributes to the literature by providing an analysis of the ability of MCDA techniques to predict the likelihood of an open market share repurchase announcement. To examine the effectiveness of the models, we used three samples consisting of 434 UK firms, 330 French firms, and 296 German firms, half of which announced a share repurchase between 1997 and 2006. The models were developed using UTADIS and ELECTRE TRI, through a ten-fold cross-validation approach. Logistic regression was also employed for benchmarking purposes. The variables were selected on the basis of theoretical reasons and past studies in the repurchasing literature. To account for differences across countries we developed country specific models. Thus, three models for each country are developed, resulting in a total of 9 models.

Our results indicated that the firm characteristics that can be useful in discriminating between the two groups of firms vary among countries which may be 
related to country-specific attributes that influence the managerial decisions with regards to share repurchases. We also found that these may differ across the methods used to develop the models. However, this is not surprising and it has been the case in past studies from other disciplines as well (e.g. prediction of acquisitions, bankruptcy prediction, etc). For example, firm size appeared to be the most important variable in the three models developed through the ELECTRE TRI method as well as in the UTADIS-UK model, while at the same time it was one of the most important variables in the UTADIS models developed for Germany and France. In contrast, $R O A$ was quite important in the UTADIS-UK model, while being considerably less important in the remaining models.

As it concerns the classification ability of the models, the average results over the 10 replications in the validation set showed that all models achieve quite balanced accuracies between the two groups and they performed better than a naïve model based on random assignment to outcomes based on prior probabilities (i.e. 50\% in an equal sample). The highest overall accuracy among all the three sample countries was achieved in France. In this case, UTADIS managed to classify correct approximately 8 out of the 10 firms, a performance that was slightly better than that of ELECTRE TRI. In contrast, in the case of the UK, it was ELECTRE TRI that performed slightly better than UTADIS. In general, the lowest accuracies were observed in the case of Germany, with the MCDA models achieving quite similar accuracies.

The satisfactory performance of the MCDA models in the validation dataset illustrates that they could be used for the classification of any new firm not included in the training sample. For example, the developed models could be of use to various decision makers such as investment managers, firm managers, and stockholders, by providing objective information that can be prove useful in an initial screening of the firms. This could result in important savings in terms of time and money.

Future research could extend the present study towards various directions such as the testing of the usefulness of the models in other countries, the employment of and comparison with alternative methods (i.e. support vector machines, neural networks, etc), and the combination of MCDA and other methods into integrated models. It could also consider the use of non-financial variables (e.g. corporate governance) and the development of decision support systems. 


\section{Acknowledgement}

The authors would like to thank the referees for numerous constructive comments. Special thanks are also due to Michael Doumpos for his insight into the employed differential evolution optimization algorithm.

\section{References}

Allen, F., Michaely, R., 2003. Payout Policy. in: Constantinides, G.M., Harris, M., Stulz, R.M. (Ed.), Handbook of the Economics of Finance, 1 (1), Pages 337429

Andriosopoulos, D., (2011), The determinants of share repurchases in Europe, Hull University, mimeo, Available at SSRN: http://ssrn.com/abstract=1559833.

Barnes, P., (1999), Predicting UK takeover targets: Some methodological issues and an empirical study. Review of Quantitative Finance and Accounting, 12 (3), 283-301.

Bagwell, L.S., Shoven, J.B., (1988), Share repurchases and acquisitions: an analysis of which firms participate. in: Auerbach, A. (Ed.), Corporate Takeovers: Causes and Consequences, 191-220.

Bagwell, L.S., Shoven, J.B., (1989), Cash distributions to shareholders. Journal of Economic perspectives 3 (3), 129-140.

Baker, H.K., Powell, G.E., Veit, E.T., (2003), Why companies use open-market repurchases: A managerial perspective, Quarterly Review of Economics and Finance 43 (3), 483-503.

Barth, M. E., Kasznik, R., (1999), Share Repurchases and intangible assets. Journal of Accounting and Economics 28 (2), 211-241.

Brounen, D., De Jong, A., Koedjik, K., (2004), Corporate finance in Europe: Confronting theory with practice. Journal of Financial Management 33 (4), 61101.

Dittmar, A.K., (2000), Why do firms repurchase stock? Journal of Business, 73 (3), 331-335.

Doumpos, M., Zopounidis, C., (2001), Assessing financial risks using a multicriteria sorting procedure: the case of country risk assessment, Omega, 29 (1), 97-109.

Doumpos M., Zopounidis C., (2004a), A multicriteria classification approach based on pairwise comparisons, European Journal of Operational Research, 158 (2), 378-389.

Doumpos, M., Zopounidis, C., (2004b), Developing sorting models using preference disaggregation analysis: An experimental investigation, European Journal of Operational Research, 154 (3), 585-598.

Doumpos M., Zopounidis C., (2011), Preference disaggregation and statistical learning for multicritteria decision support: A review, European Journal of Operational Research, 209 (3), 203-214.

Doumpos, M., Marinakis, Y., Marinaki, M., Zopounidis, C., (2009), An evolutionary approach to construction of outranking models for multicriteria classification: The case of the ELECTRE TRI method, European Journal of Operational Research, 199 (2), 496-505.

Ginglinger, E., L'Her, J-F., (2006), Ownership structure and open market stock 
repurchases in France. European Journal of Finance 12 (1), 77-94

Grullon, G., Ikenberry, D.L., (2000), What do we know about stock repurchases? Journal of Applied Corporate Finance, 13 (1), 31-51

Grullon, G., Michaely, R., (2002), Dividends, share repurchases, and the substitution hypothesis, Journal of Finance 57 (4), 1649-1684.

Grullon, G., Michaely, R., (2004), The information content of share repurchase programs, Journal of Finance, 59 (2), 651-680.

Hovakimian, A., Opler, T., Titman, S., (2001), The debt-equity choice, Journal of Financial and Quantitative Analysis, 36 (1), 1-24.

Huang-Hsi H., Wang C-P., Lin K-H., (2010), Does corporate governance affect institutional ownership and share repurchase decisions? Global Journal of Business Research, 4 (4), 35-40.

Ikenberry, D., Lakonishok, J., Vermaelen, T., (1995), Market underreaction to open market share repurchases, Journal of Financial Economics, 39 (2), 181-208.

Ikenberry, D., Lakonishok, J., Vermaelen, T., (2000). Stock repurchases in Canada: Performance and strategic trading, Journal of Finance, 55 (5), 2373-2397.

Ioannidis, C., Pasiouras, F., Zopounidis, C., (2010), Assessing bank soundness with classification techniques, Omega, 38 (5), 345-357.

Jagannathan, M., Stephens, C., (2003), Motives for multiple open-market repurchase programmes, Journal of the Financial Management Association, 32 (2), 71-91.

Jacquet-Lagrèze, E., Siskos, J., (1982), Assessing a set of additive utility functions for multicriteria decision making: The UTA method, European Journal of Operational Research, 10 (2), 151-164.

Jacquet-Lagrèze, E., Siskos, J., (1983), Méthode de decision multicritère, Editions Hommes et Techniques, Paris.

Jacquet-Lagrèze, E., Siskos, J., (2001), Preference disaggregation: Twenty years of MCDA experience, European Journal of Operational Research, 130 (2), 233-245.

Kocagil, A.E., A. Reyngold, R.M. Stein and E. Ibarra, 2002, Moody's RiskCalc ${ }^{\mathrm{TM}}$ Model For Privately-Held U.S. Banks, Moody's Investors Service, Global Credit Research, July.

Laitinen E.K, Laitinen T., (1998), Qualified audit reports in Finland: evidence from large companies, European Accounting Review, 7(4), 639-653.

La Porta, R., Lopez-de-Silanes, F., Shleifer, A., (1999), Corporate ownership around the world, Journal of Finance 54 (2), 471-517

Lasfer, M.A., (2005), The market valuation of share repurchases in Europe, Working Paper, Cass Business School, London.

McNally, W.J., (1999), Open Market Stock Repurchase Signaling, Journal of Financial Management, 28 (2), 55-67.

McNally, W.J., Smith, B.F., (2007), Long-run returns following open market share repurchases, Journal of Banking \& Finance, 31 (3), 703-717.

Mitchell, J.D., Dharmawan, G.V., (2007), Incentives for on-market buy-backs: Evidence from a transparent buy-back regime, Journal of Corporate Finance 13 (1), 146-169.

Opler, T., Titman, S., (1993), The Determinants of Leveraged Buyout Activity: Free Cash Flow vs. Financial Distress Costs, Journal of Finance, 48 (5), 1985-1999.

Ouzounis G., Gaganis C., Zopounidis C., (2009), Prediction of acquisitions and portfolio returns, International Journal of Banking, Accounting and Finance, 1 (4), 381-406. 
Palepu, K.G., 1986, Predicting Takeover Targets: A Methodological and Empirical Analysis, Journal of Accounting and Economics, 8 (1), 3-35.

Pasiouras, F., Gaganis, C., Zopounidis, C., (2007a), Multicriteria decision support methodologies for auditing decisions: The case of qualified audit reports in the UK, European Journal of Operational Research, 180 (3), 1317-1330.

Pasiouras, F., Tanna, S., Zopounidis, C., (2007b), The identification of acquisition targets in the EU banking industry: An application of multicriteria approaches, International Review of Financial Analysis, 16 (3), 262-281.

Powell R.G., (1997), Modelling Takeover Likelihood, Journal of Business Finance and Accounting, 24 (7-8), 1009-1030.

Ramamoorti S., Bailey AD., Traver R.O., (1999), Risk assessment in internal auditing: a neural network approach, International Journal of Intelligent Systems in Accounting, Finance and Management, 8 (3), 159-180.

Roy, B., Bouyssou, D., (1993), Aide Multicritère à la Décision: Méthodes et Cas, Economica, Paris.

Vermaelen, T., (1981), Common stock repurchases and market signaling, Journal of Financial Economics, 9 (2), 139-183.

von Eije H., Megginson W.L., (2008), Dividends and share repurchases in the European Union, Journal of Financial Economics, 89 (2), 347-374.

Zopounidis C., Doumpos M., (2000), Building additive utilities for multi-group hierarchical discrimination: The M.H.DIS method, Optimization Methods and Software, 14 (3), 219-240. 
Table 1- Sample distribution by country and year

\begin{tabular}{ccccc}
\hline & United Kingdom & France & Germany & Total \\
\hline 1997 & 16 & 2 & 0 & 18 \\
1998 & 38 & 28 & 0 & 66 \\
1999 & 28 & 32 & 16 & 76 \\
2000 & 26 & 52 & 36 & 114 \\
2001 & 42 & 26 & 60 & 128 \\
2002 & 62 & 50 & 46 & 158 \\
2003 & 48 & 44 & 26 & 118 \\
2004 & 60 & 40 & 28 & 128 \\
2005 & 60 & 18 & 46 & 124 \\
2006 & 54 & 38 & 38 & 130 \\
Total & 434 & 330 & 296 & 1,060 \\
\hline
\end{tabular}


Table 2 - Descriptive Statistics \& Kurskal-Wallis test

\begin{tabular}{|c|c|c|c|c|c|}
\hline \multirow[t]{2}{*}{$\begin{array}{l}\text { United } \\
\text { Kingdom } \\
\end{array}$} & \multicolumn{2}{|c|}{ Non-share repurchasing } & \multicolumn{2}{|c|}{ Share repurchasing } & \multirow[b]{2}{*}{$\begin{array}{c}\text { Kruskal - Wallis } \\
\text { (p-value) }\end{array}$} \\
\hline & Median & Std. Dev. & Median & Std. Dev. & \\
\hline Cash & 0.067 & 1.257 & 0.107 & 0.106 & 0.000 \\
\hline $\begin{array}{l}\text { Free Cash Flow } \\
\text { Dummy }\end{array}$ & 0.000 & 0.392 & 0.000 & 0.474 & 0.000 \\
\hline Cash Dividends & 0.000 & 15.077 & 0.000 & 870.860 & 0.442 \\
\hline Dividend Yield & 1.016 & 2.280 & 3.009 & 2.691 & 0.000 \\
\hline Leverage & 0.122 & 0.391 & 0.203 & 0.179 & 0.016 \\
\hline MKBK & 1.590 & 8.500 & 1.570 & 31.762 & 0.564 \\
\hline Size & 11.322 & 2.494 & 14.130 & 2.506 & 0.000 \\
\hline ROA & 0.015 & 0.687 & 0.044 & 0.156 & 0.000 \\
\hline \multirow[t]{2}{*}{ France } & \multicolumn{2}{|c|}{ Non-share repurchasing } & \multicolumn{2}{|c|}{ Share repurchasing } & \\
\hline & Median & Std. Dev. & Median & Std. Dev. & $\begin{array}{c}\text { Kruskal-Wallis } \\
\text { (p-value) }\end{array}$ \\
\hline Cash & 0.107 & 0.189 & 0.101 & 0.074 & 0.152 \\
\hline $\begin{array}{l}\text { Free Cash Flow } \\
\text { Dummy }\end{array}$ & 0.000 & 0.371 & 0.000 & 0.487 & 0.000 \\
\hline Cash Dividends & 0.000 & 2.787 & 0.151 & 310.592 & 0.003 \\
\hline Dividend Yield & 1.304 & 2.040 & 1.591 & 1.601 & 0.021 \\
\hline Leverage & 0.183 & 0.177 & 0.209 & 0.144 & 0.099 \\
\hline MKBK & 1.865 & 26.092 & 2.110 & 3.212 & 0.078 \\
\hline Size & 10.988 & 1.803 & 14.209 & 2.292 & 0.000 \\
\hline ROA & 0.031 & 0.141 & 0.029 & 0.092 & 0.226 \\
\hline \multirow[t]{2}{*}{ Germany } & \multicolumn{2}{|c|}{ Non-share repurchasing } & \multicolumn{2}{|c|}{ Share repurchasing } & \\
\hline & Median & Std. Dev. & Median & Std. Dev. & $\begin{array}{c}\text { Kruskal - Wallis } \\
\text { (p-value) }\end{array}$ \\
\hline Cash & 0.099 & 0.231 & 0.119 & 0.113 & 0.063 \\
\hline $\begin{array}{l}\text { Free Cash Flow } \\
\text { Dummy }\end{array}$ & 0.000 & 0.467 & 0.000 & 0.472 & 0.804 \\
\hline Cash Dividends & 0.000 & 1.549 & 0.000 & 11.412 & 0.007 \\
\hline Dividend Yield & 0.338 & 1.879 & 1.289 & 1.714 & 0.008 \\
\hline Leverage & 0.163 & 0.190 & 0.099 & 0.139 & 0.020 \\
\hline MKBK & 1.850 & 2.910 & 2.210 & 2.907 & 0.005 \\
\hline Size & 11.291 & 1.871 & 12.689 & 2.381 & 0.000 \\
\hline ROA & 0.015 & 0.260 & 0.032 & 0.127 & 0.003 \\
\hline
\end{tabular}

Notes: Cash is the ratio of net operating income before taxes and depreciation to total assets. Free Cash Flow dummy is a dummy variable that takes the value of one for firms that have simultaneously low Tobin's $q$ (lower than the median $q$ of a firm's respective industry for each respective year) and high cash flow (higher than the median cash flow of the respective industry for each year). Cash Dividends is the ratio of total regular cash dividends relative to net income. Dividend Yield is the ratio of total cash dividends to the market value of equity at the year-end prior to the repurchase announcement. MKBK is the market-to-book ratio. Leverage is the ratio of total debt to total assets. Size is the natural logarithm of a firm's total assets. ROA is the ratio of net income to total assets. 
Table 3- Weights of criteria (averages over 10 replications, in \%)

\begin{tabular}{lcccccc}
\hline & \multicolumn{2}{c}{ United Kingdom } & \multicolumn{2}{c}{ France } & \multicolumn{2}{c}{ Germany } \\
\hline & UTADIS & $\begin{array}{c}\text { ELECTRE } \\
\text { TRI }\end{array}$ & UTADIS & $\begin{array}{c}\text { ELECTRE } \\
\text { TRI }\end{array}$ & UTADIS & $\begin{array}{c}\text { ELECTRE } \\
\text { TRI }\end{array}$ \\
\hline Cash & 0.00 & 6.22 & 9.56 & 7.13 & 1.17 & 8.92 \\
Free Cash Flow & 0.00 & 0.03 & 0.00 & 1.93 & 1.47 & 9.58 \\
Dummy & & 29.20 & 62.80 & 13.34 & 41.79 & 17.23 \\
Cash Dividends & 12.04 & 1.70 & 0.99 & 3.27 & 24.73 & 21.17 \\
Dividend Yield & 1.70 & 8.66 & 0.05 & 8.06 & 0.00 & 1.91 \\
Leverage & 0.00 & 13.78 & 10.78 & 12.07 & 7.24 & 9.08 \\
MKBK & 1.06 & 36.07 & 15.23 & 48.50 & 23.53 & 25.69 \\
Size & 49.33 & 4.33 & 0.60 & 5.69 & 0.08 & 6.41 \\
ROA & 35.86 & & & & & \\
\hline
\end{tabular}

Notes: Cash is the ratio of net operating income before taxes and depreciation to total assets. Free Cash Flow dummy is a dummy variable that takes the value of one for firms that have simultaneously low Tobin's $q$ (lower than the median $q$ of a firm's respective industry for each respective year) and high cash flow (higher than the median cash flow of the respective industry for each year). Cash Dividends is the ratio of total regular cash dividends relative to net income. Dividend Yield is the ratio of total cash dividends to the market value of equity at the year-end prior to the repurchase announcement. MKBK is the market-to-book ratio. Leverage is the ratio of total debt to total assets. Size is the natural logarithm of a firm's total assets. ROA is the ratio of net income to total assets. 
Table 4 - Table - Classification accuracies over 10 replications (in \%)

\begin{tabular}{|c|c|c|c|c|c|c|c|c|c|}
\hline \multirow{3}{*}{\multicolumn{2}{|c|}{ Panel A: Training sample }} & \multicolumn{3}{|c|}{ Inited Kingdom } & \multicolumn{2}{|l|}{ France } & \multicolumn{3}{|c|}{ Germany } \\
\hline & & & & & & & & & \\
\hline & & Group & Overall & Group & Group & Overall & Group & Group & Overall \\
\hline & 1 & 2 & & 1 & 2 & & 1 & 2 & \\
\hline UTADIS & 74.03 & 72.28 & 73.16 & 80.54 & 73.34 & 76.95 & 72.18 & 63.16 & 67.68 \\
\hline ELECTRE TRI & 79.78 & 69.92 & 74.85 & 81.17 & 74.86 & 78.02 & 67.09 & 65.24 & 66.17 \\
\hline Logistic Reg. & 69.96 & 74.84 & 72.40 & 78.96 & 73.53 & 77.15 & 69.46 & 66.23 & 67.84 \\
\hline \multicolumn{10}{|c|}{ Panel B: Validation Sample } \\
\hline & Group & Group & Overall & Group & Group & Overall & Group & Group & Overall \\
\hline & 1 & 2 & & 1 & 2 & & 1 & 2 & \\
\hline UTADIS & 73.63 & 71.99 & 72.81 & 79.74 & 74.18 & 76.96 & 68.92 & 63.35 & 66.14 \\
\hline ELECTRE TRI & 78.29 & 68.93 & 73.61 & 77.26 & 71.57 & 74.42 & 67.09 & 65.24 & 66.16 \\
\hline Logistic Reg. & 67.73 & 75.76 & 71.74 & 76.6 & 70.68 & 73.64 & 64.71 & 61.92 & 63.31 \\
\hline
\end{tabular}

